\title{
An Examination of Citizen Involvement in Crime Prevention in High-Risk Versus Low- to Moderate-Risk Neighborhoods
}

\author{
April Pattavina \\ James M. Byrne \\ Luis Garcia
}

\begin{abstract}
In the following study, the authors examine factors that explain citizen participation in crime prevention activities in Boston. Using survey data from a random sample, census data, and official crime and arrest data, the authors identified a wide range of individualand community-based indicators that could potentially explain citizen involvement in crime prevention. Findings revealed that citizen involvement in collective crime prevention does indeed vary by the risk level of a particular neighborhood, with high-riskneighborhoods demonstrating higher rates of involvement than low-to moderate-risk neighborhoods. The authors also found that the factors that explained citizen participation varied by the risk level of the neighborhood. Overall, this research demonstrated that in high-risk neighborhoods, citizen involvement in crime prevention activities is affected by the unique blend of personal, parochial, and public social control mechanisms operating in these areas.
\end{abstract}

Keywords: crime prevention; new parochialism; citizen involvement; neighborhood

In 2003 , approximately $3.2 \%$ of all U.S. residents ( 1 in 32 adults) were under some form of correctional control. Although the vast majority of these 6.9 million adult offenders were being controlled in the community, very little attention has been focused on the types of communities in which these offenders reside and the consequences of offender location for both offenders and communities. However, recent federal government reentry initiatives have begun to shed considerable light on this issue. Byrne and Taxman (2004), for example, report that more than half of the 600,000 inmates released from prison in 2002 were from five states (California, Florida, Illinois, New York, and Texas); in these states, most offenders are returning to a relatively small number of urban, high-risk neighborhoods. Even though

APRIL PATTAVINA: Department of Criminal Justice, University of Massachusetts-Lowell. JAMES M. BYRNE: Department of Criminal Justice, University of Massachusetts-Lowell. LUIS GARCIA: Department of Sociology, Suffolk University.

CRIME \& DELINQUENCY, Vol. 52 No. 2, April 2006 203-231

DOI: $10.1177 / 0011128705284155$

() 2006 Sage Publications 
much has been written about how offenders affect communities (both when they leave for prison and when they return from prison), much less attention has been focused on the effect of communities on offenders, not only in terms of resource availability (e.g., jobs, housing, and treatment) but also in terms of the appropriate role of residents in community surveillance and control activities.

One of the most often-cited studies of "person-environment interactions" was conducted by Gottfredson and Taylor (1986). In this study of the behavior of parolees released to 1 of 90 Baltimore neighborhoods, the researchers found support for "what Olweus called the person-environment integrity orientation ... that is, we believe that the person, his/her environment, and his/ her behavior interact in a process of mutual and reciprocal influence, and that these processes are an integral part of the environment" (p. 147). Gottfredson and Taylor found that an individual offender's risk of recidivism was indeed influenced by the type of neighborhood to which he or she was released. ${ }^{1}$ They found that "bad risk offenders fail more seriously when released to bad environments and do better if released to good environments"(p. 148). However, they also found that "good risk offenders do better in poorer environments and more poorly in better ones" (p. 148). These findings suggest that there is more going on here than we would anticipate from a traditional interpretation of social disorganization theory, where both high- and low-risk offenders would be expected to do worse in high-risk neighborhoods and better in low-risk neighborhoods. Gottfredson and Taylor argue that the most likely explanation is that there is a differential surveillance and control model operating in these neighborhoods; both residents (via informal surveillance or control activities) and the police (via formal surveillance or control activities) respond differently to high-risk (and low-risk) offenders in different (high- vs. low-risk) neighborhoods:

In "bad" environments, there not only may be opportunities for failure, but there might also be considerably more formal (i.e. police-initiated) surveillance. Further, such surveillance might well be targeted on offenders with extensive criminal records. If so, reliance on surveillance by policing authorities could easily result in the pattern observed here: "good risk" offenders do better, and "poor risk" offenders more poorly, in socially disorganized environments. In better (more socially organized) environments, there may be less reliance on formal surveillance-control mechanisms, and an increased reliance on informal surveillance and control. Accordingly, "bad risk" offenders (perhaps not known to police) do relatively better (they still do quite poorly, but in fact do better in better neighborhoods). "Good risk" offenders, on the other hand, do somewhat worse in the better neighborhoods. Although they may be "under-watched" by policing authorities, they may be watched by their neighbors. (p. 149) 
The interplay between formal and informal surveillance and control mechanisms is critical to the success of current offender reentry initiatives, but it appears that there has been inadequate consideration on how formal and informal surveillance and control mechanisms affect different types of offenders (e.g., high vs. low risk) in different types of communities (e.g., high crime vs. low crime). The involvement of residents in maintaining public safety in their communities has long been a subject of interest to the criminal justice community. During the past 25 years, scholarship on this topic has evolved along parallel theoretical and political dimensions. Recent theoretical advances, grounded in social disorganization theory, have served to both refine and expand the conceptual framework associated with informal social control in neighborhoods and how it operates to suppress crime (Bursik \& Grasmick, 1993; Sampson \& Groves, 1989; Sampson, Raudenbush, \& Earls, 1997). According to this contemporary theoretical framework, residents manage crime risk through dense social ties and shared values that work to protect neighborhoods through residents' willingness to engage in direct neighborhood supervision. Moreover, neighborhoods with this regulatory capacity are also able to sustain an array of private, parochial, and public relational networks that assist in securing external resources for dealing with crime and disorder.

The political component of crime risk management has centered on the adoption of the community policing philosophy of crime prevention and control. Based on this framework, the role of the residents in crime risk management is described as one where citizens are "coproducers" of public safety along with the police. The resulting crime control model suggests a more hybrid form of social control, one that combines local policing efforts with citizens in managing crime risk. This form of community crime control is an example of what Carr (2003) refers to as the "new parochialism." Carr argues that opportunities for direct engagement in managing crime risk may come not as a result of dense social ties and they may not be manifested in direct neighborhood supervision; instead, opportunities for citizen participation are facilitated through public agents of control such as the police. Residents manage crime risk through indirect involvement, participating in groupbased, organization-sponsored, or endorsed activities that work in concert with police. Of course, it should be recognized that these types of parochial activities are generally surveillance and control oriented, essentially offering police an extra set of eyes and ears in the community. They are not designed to mobilize the community to address the underlying community-level problems (e.g., poverty, inequality, culture) that have been linked to neighborhoods with persistently high crime rates during several decades (Sampson \& Morenoff, 2006). 
Carr's (2003) work offers important insight for examining how residents respond to crime in their communities. What he could not examine in his ethnographic study of one Chicago neighborhood was how the new parochialism may be influenced by neighborhood disadvantage. Research has consistently demonstrated that there is a nexus between race, poverty, and crime operating at the neighborhood level (Sampson \& Morenoff, 2006), and the literature on community policing suggests that there are many competing hypotheses about the possible nature of the relationship between neighborhood disadvantage and involvement in crime prevention (Buerger, 1994b).

Some scholars suggest that the disadvantaged neighborhoods will experience lower levels of involvement because of poor relationships with and lack of trust in the police from minorities (Kane, 2005; Sherman, 2002). Kane (2005), for example, describes the cultural attenuation framework that would "predict a relationship between extreme structural disadvantage and crime through the development of strong informal social control networks that may be based on cynicism, social dislocation and the use of physical domination for self protection and earning respect" (p. 475). Others claim that involvement is likely to be greater in these high-risk neighborhoods, where residents are likely to get involved because they feel the police can do little to stop crime without their assistance (Carr, 2003).

The purpose of this article is to contribute to the discussion of neighborhood disadvantage and residents' management of crime risk. We will empirically investigate the extent to which neighborhoods with low to moderate and high crime levels manifest evidence of the new parochialism Carr (2003) described in his ethnographic research. Using data from a 1997 public safety survey in the city of Boston, along with official crime rates, we examine the interaction between neighborhood crime and individual-level factors as they relate to involvement in collective crime prevention. By comparing the factors that explain citizen involvement in high-crime areas to the factors that explain citizen involvement in low- to moderate-crime areas, we hope to shed light on the issues related to citizen involvement in crime prevention and control activities in high-risk neighborhoods (e.g., a focus on the surveillance and control of offenders vs. a focus on strategies designed to address the underlying community context of crime).

If the early work of Gottfredson and Taylor (1986) is accurate, then the implications of a differential surveillance-control model operating in highrisk and low-risk neighborhoods are important to understand. In particular, the notion that high-risk offenders released from prison to high-risk neighborhoods may have higher probabilities of surveillance and control (and risk of apprehension) than high-risk offenders released from prison to low-risk neighborhoods suggests that policy makers may need to reframe the offender 
reentry problem in recognition of the interaction between offender and community risk level. When viewed in this context, citizen involvement in crime prevention activities - at the parochial level—in high-risk communities may not necessarily be good for either offenders or communities because such involvement may contribute both to the return of released offenders to prison and the further breakdown of informal social controls in these neighborhoods.

\section{LITERATURE REVIEW: THE COMMUNITY CONTEXT OF CITIZEN INVOLVEMENT IN CRIME PREVENTION ACTIVITIES}

The idea that citizens have a role to play in maintaining the safety of their communities has a long-standing tradition in criminal justice theory and policy. The major theoretical argument behind this claim is that people who live together in the same community possess a synergistic capacity to regulate the behavior that occurs in that community. This premise is a fundamental component to the concept of informal social control and has come to be known as one of the central tenets of the social disorganization theory originally formulated by Shaw and McKay (1942). In the past 25 years, there has been a considerable amount of research published on this subject (see Bursik, 1988; Bursik \& Grasmick, 1993; Byrne \& Sampson, 1986; Kubrin \& Weitzer, 2003).

There has also been a significant effect of social disorganization theory on criminal justice policy. Particularly noteworthy has been the influence of social disorganization on the evolving philosophy supporting modern community policing. The community policing philosophy advocates that citizens and the police share the responsibility for public safety. An examination of the convergence of social disorganization theory with community crime prevention policies, we believe, offers considerable insight into current thinking about the role of citizens and police in managing crime risk in the community.

Shaw and McKay's (1942) notion of informal social control was never explicitly defined or measured in their seminal work. It was, however, theorized to be the product of neighborhood structural characteristics such as poverty, racial and ethnic heterogeneity, and residential mobility. Neighborhoods lacking in informal control were at risk of having high levels of crime. Indeed, many studies have found these neighborhood conditions to be associated with crime (see reviews in Bursik, 1988; Sampson \& Wilson, 1995; Sampson \& Lauritsen, 1994).

More recent studies have sought to advance social disorganization theory in several important ways. For example, some researchers have focused on 
the definition and measurement of specific processes associated with informal control in neighborhoods and how they influence crime. Sampson et al. (1997) argue that informal social control is manifested in what they call collective efficacy, defined as a combination of shared values and a willingness to act. Their research shows that collective efficacy mediates neighborhood structural conditions related to crime, even after controlling for prior levels of violence. From this perspective, the ability to manage crime risk is organic and develops separately from the influence of formal social control mechanisms.

The fact that neighborhood social dynamics that lead to crime are tied to larger economic, political, and social forces was advanced by Bursik and Grasmick (1993) in a reformulation of social disorganization as a systemic model of social control. They argued that a neighborhood's internal capacity for self-regulation can be explained through a model where relational networks operate on three levels: private, parochial, and public. Private networks are relations among intimate groups such as family and friends. Parochial networks are broader interpersonal ties that are local in nature and intersect with institutions such as stores, churches, schools, and voluntary organizations. Public networks support a community's capacity to secure services and public goods from external agencies such as the police.

The ability to manage risk is based on a multilevel model of social networks both inside and outside the neighborhood that provide residents with means to secure resources necessary to deal with crime and related problems. Neighborhoods without these network capabilities suffer most from disinvestment and are ultimately at the greatest risk of crime. The structural characteristics hypothesized to affect levels of informal social control (and how they are tied to larger political and economic contexts) offer perhaps the best available explanation for the growing concentration of disadvantage in many inner-city communities (Sampson \& Morenoff, 2004).

A key claim associated with Shaw and McKay's (1942) work was that structural conditions lead to rapid changes in population turnover, which created neighborhood instability. The economy at the time of Shaw and McKay's research was dominated largely by the manufacturing industry. New immigrants were attracted to the low-skilled industrial jobs and the cheap housing in northern inner-city neighborhoods. Once economically stable, they moved to more desirable housing elsewhere, creating a cycle of rapid population turnover, instability, lack of social control, and crime.

The economic structure responsible for rapid population turnover, however, did not last. The work of William Julius Wilson (1996) documents the movement of manufacturing jobs out of the northern cities, which dramati- 
cally changed employment prospects for city residents, especially among the low-skilled workers. Although he would agree with Shaw and McKay's (1942) premise that economic opportunity was a destabilizing factor in city neighborhoods, the process by which it led to instability changed over time. Where economic mobility and growth were once significant sources of instability, because they led to residential turnover in the industrial age of Shaw and McKay, now economic disinvestment was the dominant and destabilizing factor in cities, in large part because it undermined the capacity of minorities left behind to secure meaningful employment, serve as important role models, and provide stable family environments. In general terms, lack of opportunity meant no economic mobility and ultimately led to a growing concentration of disenfranchised minority residents. The result has been the nexus of race, poverty, and crime that now characterizes the "poverty pockets" and durable inequality found in many inner-city neighborhoods (Sampson \& Morenoff, 2006).

\section{Community Policing Versus}

Community Change Strategies

Rather than attempting to address large-scale structural changes needed to stem the tide of social and economic disinvestment, policy makers instead turned their attention to the law enforcement community for answers to the crime problems plaguing many cities in the United States. During the past two decades, one of the major observations made by policing scholars was that the police had become estranged from the communities they served. In response, many community policing or problem-oriented policing programs were established. The goal of these programs was to bring the police back into the community and work together with citizens to manage crime risk. Under this model, the police partner with residents in identifying crimerelated problems and securing resources necessary to ameliorate those problems. The relationship is often described as one where residents and police are coproducers of public safety. Even in high-crime areas, it was argued that a combination of citizen involvement and police (pro) activity could stem the crime problem, despite the long-standing community-level problems (e.g., poverty, inequality, culture) that residents of these neighborhoods experience.

Community policing advocates made several assumptions about community policing, the most ambitious being that all communities would be interested in working with the police. In fact, one objective that Rosenbaum (1998) referred to as the implant hypothesis is that community policing activ- 
ities would facilitate the neighborhood social cohesion necessary to manage crime risk. This process would require much cooperation from neighborhood residents, and many skeptics claimed that this assumption was idealistic and unlikely to work in poor minority neighborhoods where there was a long history of poor relations with police (Buerger, 1994b). Moreover, minorities in particular and poor people in general may end up being the targets of such programs rather than benefiting from them (Skogan, 1990).

Early evaluations of community policing activities and community crime prevention efforts revealed that one of the major issues confronting advocates of this strategy was the difficulty in getting community residents to participate. In fact, a review of eight community policing programs found that each experienced difficulty in stimulating community involvement (Grinc, 1994). Furthermore, a history of political and economic disinvestment, combined with the estrangement from law enforcement, left residents in some communities skeptical about the role of the police in their communities. In these communities (particularly minority communities where tension with police was often present), there was little apparent interest in working with police. Moreover, many residents were afraid to get involved (Grinc, 1994).

Also, evidence suggesting that people likely to be involved in anticrime groups are those who have a vested interest in or attachment to the neighborhood was beginning to mount; they tend to have children, own homes, and have lived in the neighborhood for a long time (Skogan, 1990). In particular, Skogan's (1990) research on community policing in Chicago indicated that participation in anticrime groups was higher among those residents who engaged in informal surveillance (i.e., by asking neighbors for assistance and intervening in suspicious circumstances) at the private level.

One major assumption underlying community policing is that there is an untapped potential for social cohesion in all neighborhoods that community policing efforts will successfully galvanize (Buerger, 1994a). In this regard, a recent study by Kerley and Benson (2000) found that community policing tactics do not have a strong effect on community processes including community cohesion, community organization, and changes in cooperative security mechanisms believed to be central to reducing crime and fear of crime. Carr (2003), however, argues that the need for cohesion as a means to promote crime risk management on behalf of residents may be overstated. Indeed, the change in the view of the police as reactive agents to one where they are proactive and interactive expanded the possibilities in which residents might engage in social control for the purpose of managing crime risk. Carr argues that citizen involvement (in parochial-level activities) is not necessarily a consequence of the presence (or implant) of social cohesion. 


\section{Carr's New Parochialism}

Drawing on his ethnographic work in Chicago, Carr (2003) suggests that perhaps the parochial (neighborhood) and public (police) aspects of the systemic model may be inseparable, not independent as others have argued. From this perspective, informal control may be manifested through what Carr refers to as the new parochialism,

where diminished private and traditionally parochial forms of social control are replaced by behaviors that are a combination of parochial and public controls. Instead of supervision and direct physical intervention in disputes, residents engage in behaviors that are more secure and facilitated by actors from the public sphere of control. (p. 1249)

In this configuration, opportunities to engage in managing crime risk are provided at the parochial level but are organized and supported through mechanisms of public control (i.e., the police). According to Carr's research, the promotion of residential involvement in risk management and informal social control is not necessarily dependent on either the organic definition of collective efficacy as presented by Sampson et al. (1997) or on the implant community policing hypothesis of Rosenbaum (1988). Instead, a hybrid of parochial and public controls provides alternatives for residents to safely engage in crime prevention activities that are based on collective action rather than grounded in social cohesion.

Although Carr (2003) based his observations on one Chicago neighborhood, his argument offers considerable possibilities for understanding residents' decisions to become involved in collective action and community policing activities, especially in the more disadvantaged communities. Buerger (1994b) argues that in many high-crime areas, there is no untapped reservoir of social cohesion waiting to be unleashed by traditional community policing tactics. These communities suffer from high crime levels, lack cohesiveness, and have high fear levels that may prevent them from getting involved in direct personal intervention, but they may still be willing to engage in collective action. Of course, the fact that the relationship between citizens and the police in the most disadvantaged communities has historically been one of mistrust and dislike suggests that citizen involvement is affected by factors other than the public's perception of the police in these high-crime areas. Indeed, Sampson and Jeglum-Bartusch (1998) found that residents in high-crime areas tend to have negative attitudes toward the police; but when examining citizen involvement in high-crime areas, it would be a mistake to assume that such attitudes would necessarily preclude residents from becoming involved. 


\section{The Community Context of Citizen Involvement: Key Research Questions}

Our review of the research on social disorganization, community policing, and the factors explaining citizen involvement in crime prevention activities has revealed several research questions that need to be answered before the community context of citizen involvement can be fully understood.

1. To what extent does neighborhood risk, as measured by either crime or arrest rates, influence residents' decisions to engage in collective crime prevention?

2. Given the growing opportunities to engage in formally sanctioned crime prevention activities, is social cohesion a necessary condition to generate involvement in both high- and low- to moderate-risk neighborhoods?

3. How do attitudes toward community policing shape decisions to become involved in collective crime prevention in high- and low- to moderate-crime neighborhoods?

4. Do the individual neighborhood and police factors that explain citizen involvement vary by neighborhood risk level?

We briefly frame the policy issues associated with each of these research questions in the following section.

\section{Neighborhood Risk and Community Involvement}

The first question has been the subject of much debate because there have been several competing claims about the nature of this relationship. Described so far have been two competing hypotheses. The first is that high crime rates will lead to greater involvement in crime prevention because people will rally to defend their communities or act because of a lack of confidence in the police to deal with the crime problem. Second is the view that because of fear of crime or retaliation, areas with high crime rates will tend to have lower levels of involvement. Both of these claims suggest the relationship is linear. Yet a third claim is that the relationship between crime rates and involvement is likely to be positive in the face of rising crime rates but that as crime reaches a "tipping point," the level of involvement will decrease (Skogan, 1989).

There have been several studies that examined the effect of official neighborhood crime levels on involvement in community crime prevention. For example, Skogan and Hartnett (1997) found that area-level crime rates and poverty levels predicted attendance rates at public safety meetings. They also found that attendance rates were significantly lower in areas with higher percentages of Hispanic residents but not areas with higher percentages of Blacks, when other area factors were controlled. Other studies have focused on the role of opportunities to participate as an indicator of potential involve- 
ment. Smith, Novak, and Hurley (1997) examined the relationship between the number of community-based organizations that have regular interaction with police and area crime rates. They found that the number of communitybased organizations was higher in areas with high crime rates. Skogan (1989) also found evidence of a positive relationship between area-level crime rates and opportunities to get involved. Lavrakas and Herz (1982) found that urban areas with higher crime rates are more likely to contain neighborhoods where group anticrime efforts develop. Neighborhood crime rates may also shape the nature of police-citizen relationships. Schafer, Huebner, and Bynum (2003) found that area crime rates were negatively related to perceptions of traditional police services, but when specific community-policing-oriented services were considered as the outcome, the relationship was not significant once the nature of police contacts was taken into account.

These studies provide important contributions to the community crime prevention literature because they demonstrate that official neighborhood crime rates influence opportunities to participate and attitudes toward traditional police services. They are limited, however, in that they consider the effect of area crime rates to be linear and fail to capture actual involvement in collective crime prevention. In the present study, we address this limitation by examining whether actual involvement in collective crime prevention differs between neighborhoods with high crime levels and those with low to moderate crime levels.

\section{Social Cohesion and Citizen Involvement}

Social cohesion is considered to be an important indicator of the capacity of residents to engage in informal social control. There have been many refinements and varied measures related to this concept over time, the most recent being the collective efficacy measure created by Sampson et al. (1997). In general terms, these measures tend to capture the extent to which neighbors share values, can rely on each other for support, and are willing to draw on those qualities to act in ways that protect the safety of their communities. This capacity for self-regulation has been a salient predictor of criminal activity and promotes residents' close supervision of behavior in their neighborhoods (Sampson \& Groves, 1989). Research has also found social cohesion to be a significant predictor of actual involvement in formal collective crime prevention efforts sponsored by local community-based organizations (Frank, Brandl, Worden, \& Bynum, 1996).

What has not been examined, and thus serves as a basis for Question 2, is whether the effects of social cohesion on actual involvement in collective crime prevention vary across neighborhoods with high and low to moderate 
crime levels. Sampson et al. (1997) found that area measures of collective efficacy were negative predictors of crime. It may be that other factors emerge in high-crime areas as more important predictors of actual involvement in collective crime prevention. We examine this issue in the analysis that follows.

\section{Community Policing and Citizen Involvement}

With the move toward community policing and the related emphasis on partnership and collaboration among police, residents, and community organizations to prevent crime, attitudes toward police should be considered in studies attempting to explain involvement in collective crime prevention. Although it is difficult to determine which organized anticrime efforts are the product of police sponsorship and collaboration, the recent widespread adoption of community policing (Cordner, 1997) suggests that the police are more likely to be involved with these organizations and local residents than they were in the past. How residents view the police has been found to have direct effects on involvement. Scheider, Rowell, and Bezdikian (2003) found that positive perceptions of community policing were directly related to increases in crime prevention behavior. Indirectly, the visible presence of officers in a neighborhood has been found to improve residents' opinions of the police (Hawdon \& Ryan, 2003), which may in turn increase crime prevention behavior.

\section{The Community Context of Citizen Involvement}

In high-crime communities, different forces may motivate participation. For example, Carr (2003) argues that social cohesion may not be a necessary factor motivating residents to get involved. If social cohesion does not directly influence involvement in high-crime areas, then we need to examine what other factors may motivate participation in these neighborhoods. Carr further suggests that the presence of opportunities for involvement supported by formal agents of social control is sufficient to motivate participation because there are legitimate and safe venues for residents to manage crime risk. However, because the public's confidence in the police department's ability to deal with crime is questionable in high-crime areas, it is certainly possible that some other facet of police-citizen interaction explains involvement in high-crime areas.

Research suggests that the relationship between police and residents may be influenced by area crime levels. Skogan (1989) found that organized activity around crime issues was higher in areas where people did not believe 
they were getting good police service. Many have argued that in high-crime areas, attitudes toward police are likely to be negative. The study by Frank et al. (1997) found that attitudes toward police were not related to involvement once other factors were controlled. However, they did not examine the effect of variation in neighborhood crime rates on involvement by citizens. To address this issue, we investigate the relationship between attitudes toward police and actual involvement across high- and low- to moderate-risk neighborhoods.

DATA

In the following analysis, we assess whether individual-level predictors of involvement in collective crime prevention vary across neighborhoods with different levels of crime. The data are from a 1997 random telephone survey on public safety issues conducted in the city of Boston. The data set includes 2,362 responses from Boston residents. ${ }^{2}$ For this study, we defined neighborhoods as census tracts based on the boundaries available from the 1990 U.S. census. There are 163 census tracts in the city of Boston, with an average population of approximately 3,500 .

One of our primary objectives was to compare predictors of involvement in crime prevention across neighborhoods with varying levels of crime. From the Boston Police Department, we obtained incident reports for violent crime and all arrest reports for 1997. We aggregated these data to the census tract and appended them to the survey. In particular, we wanted to examine what was happening in areas with the highest levels of crime compared to other neighborhoods. We defined areas as having high crime rates if they fell at or above the 75th percentile of all neighborhoods; all neighborhoods below the 75th percentile were considered to have low to moderate crime rates.

For each neighborhood, two measures of crime were considered. One measure was the rate of incidents for violent crimes including homicide, rape, assault, and robbery per 1,000 reported to the Boston Police Department in 1997. This measure is intended to serve as a measure of actual crime. The rate ranged from 0 to 160 per 1,000 , with an average of 15 . Neighborhoods with violent incident rates of 21 per 1,000 or more were at or above the 75 th percentile and considered high-risk violence areas. The second measure, arrest rate, is considered here to be an indicator of police service. The arrest rate was calculated from 1997 Boston Police Department arrest reports and is measured as the arrest rate per 1,000 for violent crimes (heretofore listed) and property crimes including burglary, larceny, and theft. The rate ranged from 0.27 to 154 per 1,000 , with an average of $11 .{ }^{3}$ Neighborhoods 


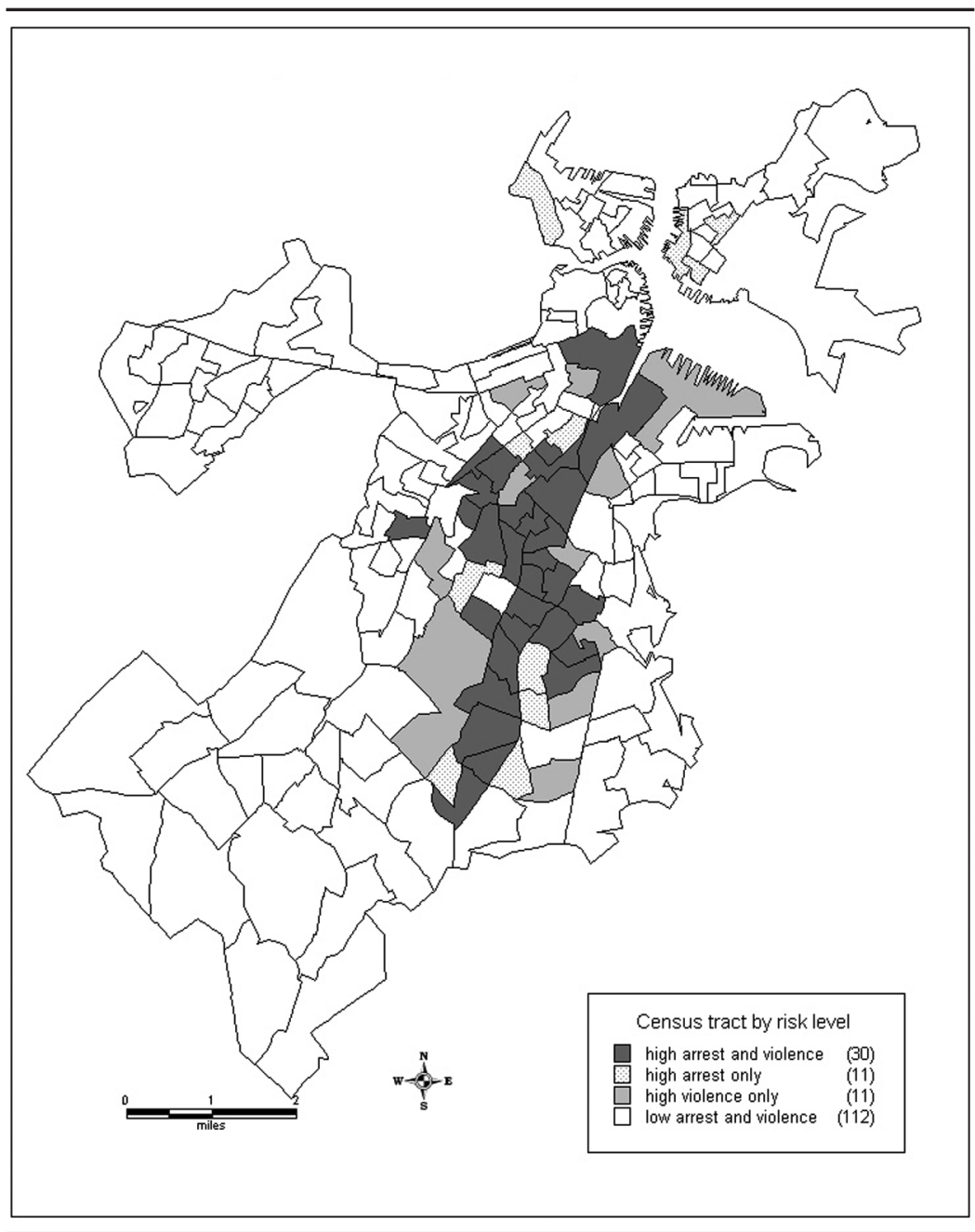

Figure 1: Boston Neighborhoods by Crime Risk Levels

with arrest rates for property and violent crime of 15 or more per 1,000 were at or above the 75th percentile and were considered high-risk arrest areas (see Figure 1).

Given the emerging literature concerning the nexus between high levels of crime and other measures of disadvantage, we examined the distribution of relevant factors including the percentage living in poverty, the percentage of single-parent families, and the percentage Black across high- and low-crime neighborhoods using a one-way analysis of variance. The results reported in 
TABLE 1: Means of Selected Structural Characteristics by Crime Levels

\begin{tabular}{|c|c|c|c|c|}
\hline & $\begin{array}{l}\text { Sample } \\
\text { Mean }^{\mathrm{a}}\end{array}$ & $\begin{array}{c}\text { Low- to } \\
\text { Moderate-Crime } \\
\text { Neighborhoods }\end{array}$ & $\begin{array}{c}\text { High-Crime } \\
\text { Neighborhoods }^{\mathrm{c}}\end{array}$ & $\begin{array}{c}\text { Mean } \\
\text { Difference }\end{array}$ \\
\hline \multicolumn{5}{|l|}{ Violent incident rates } \\
\hline$\%$ single-parent families & 23 & 18 & 39 & $21^{* *}$ \\
\hline$\%$ poverty & 20 & 17 & 29 & $12^{* *}$ \\
\hline \% Black & 25 & 15 & 56 & $40^{* *}$ \\
\hline \multicolumn{5}{|l|}{ Arrest rates } \\
\hline$\%$ single-parent families & 23 & 18 & 39 & $21^{* *}$ \\
\hline$\%$ poverty & 20 & 18 & 28 & $11^{* *}$ \\
\hline$\%$ Black & 25 & 13 & 60 & $46^{\star *}$ \\
\hline
\end{tabular}

Table 1 indicate that high-crime areas also have significantly higher levels of poverty, single-parent families, and minorities. These results support prior literature suggesting that crime and other measures of disadvantage tend to cluster together.

\section{VARIABLE SELECTION}

The dependent variable for this analysis is a measure of citizen involvement in collective crime prevention activities in their neighborhoods in the prior year. This dichotomous measure was constructed from three survey questions: (a) Have you personally done anything different during the past year to help reduce or prevent crime from occurring in your neighborhood? ${ }^{4}$ (b) Within the past year, have you attended any meetings related to public safety or crime issues in your neighborhood? (c) Do you belong to a neighborhood watch group? If a respondent answered yes to any of these questions, then he or she was assigned a value of 1 for the involvement measure $(0$ was coded for no). ${ }^{5}$

Table 2 includes the descriptives for the selected variables. In all, 39\% of the residents reported some involvement with community crime prevention. The rates of involvement varied across neighborhood crime levels and were higher in areas with greater rates of violent crime and arrests. A total of $36 \%$ of persons in the areas with low to moderate levels of violent crime and arrest rates were involved, compared to $53 \%$ in the areas with higher crime levels.

The selection of independent variables for the analysis was based on the review of current research addressing citizen involvement in community 


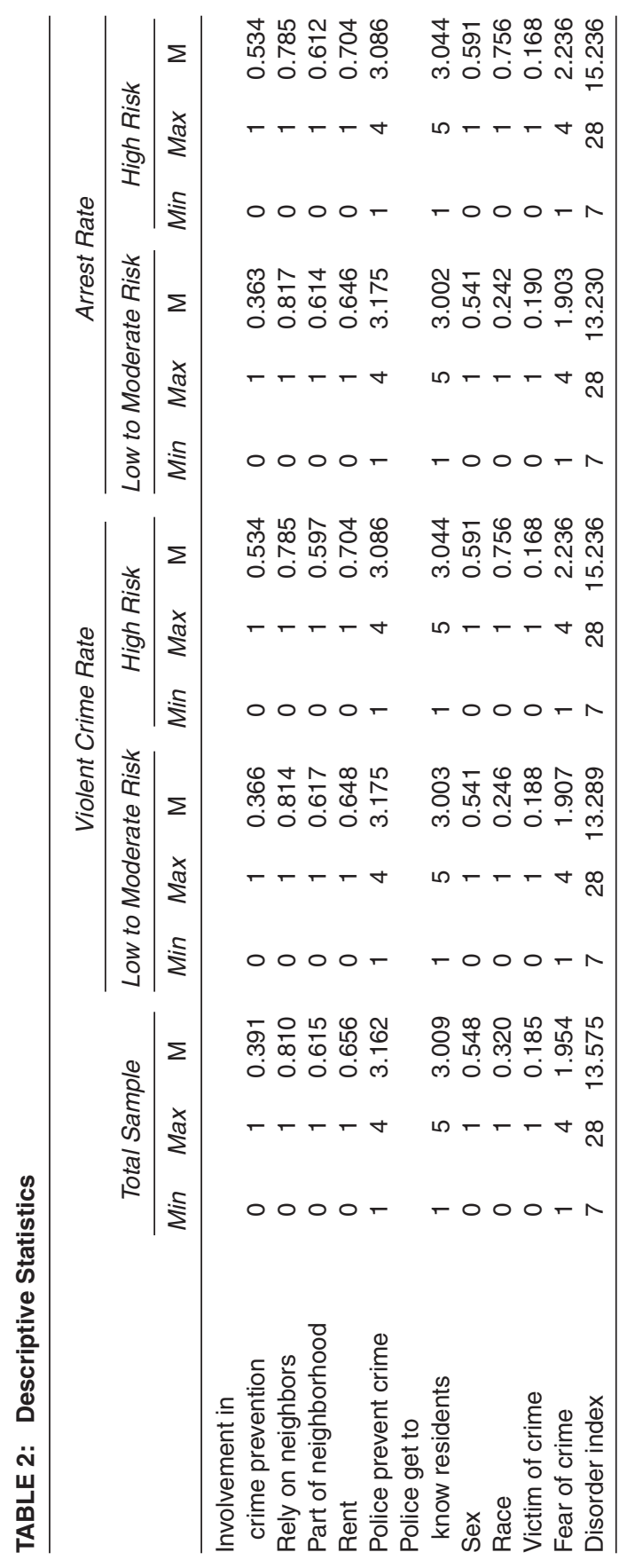


policing and crime prevention. Relevant factors include social cohesion, fear, victimization, and disorder. Three variables measuring social cohesion were considered. The first measure is a question asking the respondent if he or she felt a part of the neighborhood or whether he or she felt like it was just a place to live (coded 1 if he or she felt part of the neighborhood, 0 for just a place to live). About $60 \%$ of the sample reported that they felt like part of the neighborhood, and this was relatively consistent across all neighborhood crime levels. The second measure is whether or not the respondent could rely on his or her neighbors for help (coded 1 for yes, 0 for no). The majority of residents in all neighborhoods believed they could rely on their neighbors for help $(81 \%)$. There was only slight variation across neighborhoods, with $81 \%$ in low to moderate violence and low to moderate arrest areas believing they could rely on neighbors for help, compared to $78 \%$ for high-violence and high-arrest areas. The third measure indicates whether the resident rents or owns his or her home ( 1 for rent, 0 for own). In all, $65 \%$ of the total sample rented their homes. Those in higher violence and higher arrest areas had somewhat higher levels of renters than those in the lower violence and arrest areas $(70 \%$ vs. $65 \%)$.

Measures of fear, social disorder, and prior victimization were also included as independent variables. A localized fear measure was based on the question of how safe the respondent felt out alone in his or her neighborhood at night. The response was coded on a scale of 1 (very safe) to 4 (very unsafe). Only $7 \%$ indicated that they felt very safe alone in their neighborhood at night, and 35\% indicated that they felt very unsafe. The mean fear level was 1.9 for the sample and the low-crime areas. The average level of fear was much higher in the high-crime areas, with a mean of 2.4. Prior victimization was coded 1 if the respondent had been the victim of crime in Boston within the past year and 0 if not. In all, 19\% of the total sample indicated that they had been the victim of crime. Low-violence and low-arrest areas also had about 19\% reporting prior victimization. Interestingly, the percentage victimized in the high-violence and high-arrest areas was slightly lower, at about $17 \%$.

Perceptions of social disorder is an index created by adding together responses from a series of specific conditions that may be problems in the area where the respondents lived. The list of neighborhood conditions included in the index were perceptions of litter and trash lying around, graffiti, vacant houses and unkempt lots, people making too much noise, people drinking in public, kids hanging around, and panhandling in the neighborhood. For each condition, the respondent was asked to rate the condition from 1 (not a problem) to 4 (a serious problem). The scale ranged from 7 to 28 . The 
alpha value for this index was .788. The mean measure for the sample and the low-crime areas was 13. It was slightly higher at 15 in the high-crime areas.

We included two variables that represent citizen attitudes toward police. The first measure includes the respondents' belief that the police can actually prevent crime. This is a measure of general attitudes toward police effectiveness. The question asked respondents how much confidence they had in the ability of the police to prevent crime. The response ranged from 1 (not at all) to 4 (a great deal). The average response for the sample was 3.1, and this varied little across neighborhoods with high and low crime rates.

The second measure includes a question on the level of agreement residents have for the statement that police officers working in their neighborhood make an effort to get to know residents. This measure is intended to reflect some of the objectives embodied in community policing. Responses were coded based on a Likert-type scale ranging from 1 (strong disagreement) to 5 (strong agreement). The mean for the sample was 3 , and again this varied little across neighborhoods with high and low crime rates.

Race and sex were also included in the analysis; race was coded 0 for White respondents and 1 for Blacks, Asians, and people of other races. In all, $68 \%$ of the sample was White, compared to $32 \%$ minority. This percentage did vary across neighborhoods. In neighborhoods with low to moderate violence and arrest rates, about $24 \%$ of the respondents were minority, compared to $74 \%$ minority in the higher crime areas. Sex was coded 0 for male and 1 for female. A total of $45 \%$ of the sample was male and $55 \%$ was female. There were slightly more females in the higher crime neighborhoods (59\%) than other neighborhoods (54\%). The results thus far indicate that higher crime areas have higher levels of involvement, higher percentages of minorities, more renters, and more females than do the lower crime areas.

\section{ANALYSIS}

\section{Bivariate Results}

Table 3 includes the results of a bivariate analysis predicting resident involvement in crime prevention from each independent variable. The analyses were conducted for the entire sample, then separately for neighborhoods with low to moderate and high violent crime rates, and then separately for the neighborhoods with low to moderate and high arrest rates. Included in the results are the estimated coefficients in columns labeled $B$ and the factor by which the odds change with each unit increase in the independent variable

labeled with $\operatorname{Exp}(B)$. The results for the total sample are included in the first 


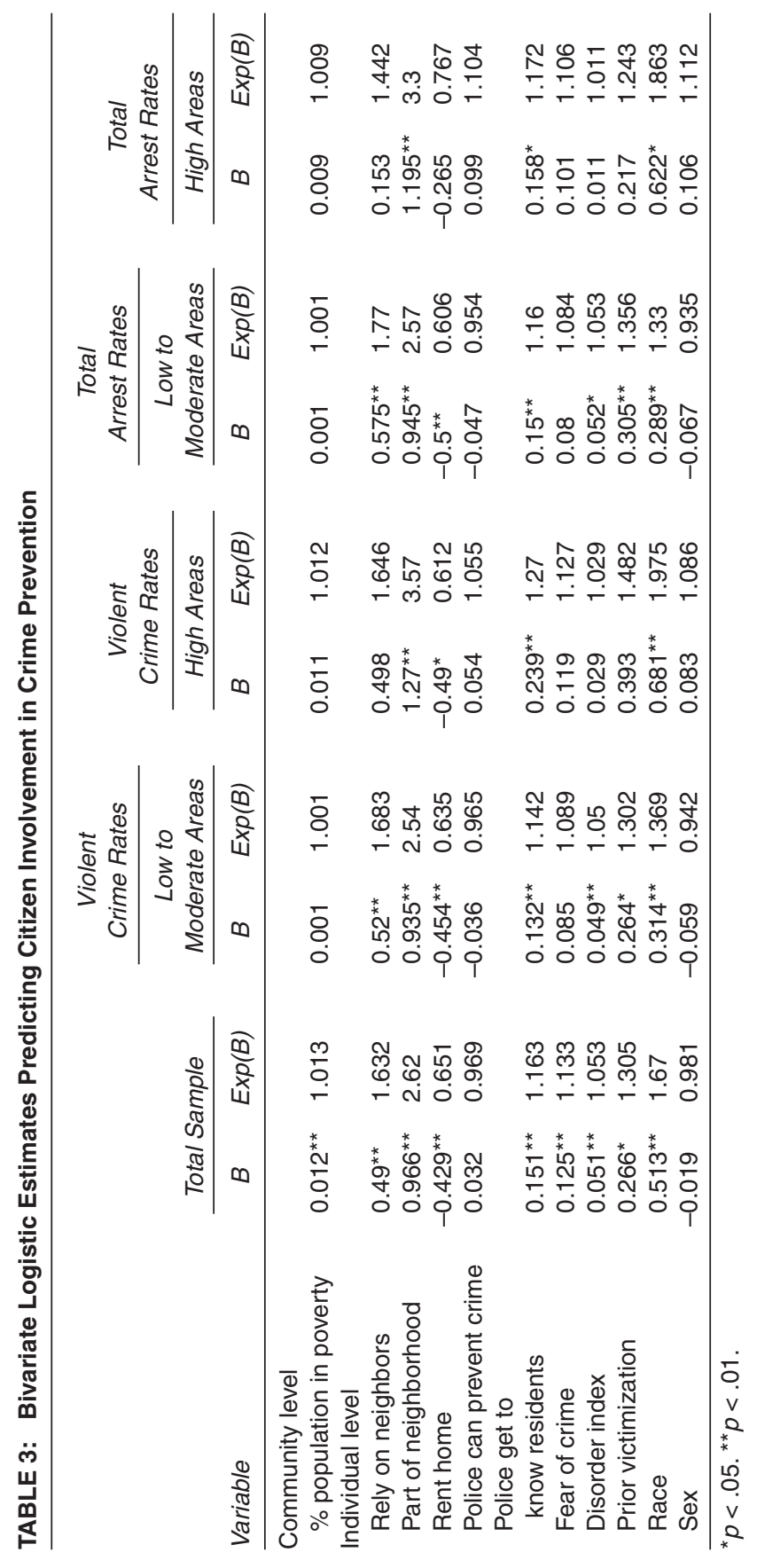


two columns and show that the percentage of neighborhood living in poverty is positively related to involvement. Those living areas with high levels of poverty are also more likely to be involved in community crime prevention. ${ }^{6}$ Both social cohesion measures and renter status are significantly related to involvement. Residents who feel like part of the neighborhood, who can rely on their neighbors for help, and who are less likely to be renters versus owners are significantly more likely to get involved in community crime prevention activities.

Only one measure of police attitudes was significant. Those who agree that the police make an effort to get to know residents are significantly more likely to be involved in community crime prevention than are those who do not agree. Persons who have higher levels of fear, those who have been victimized in the past year, and those who perceive high levels of social disorder are also likely to be involved in community crime prevention. Minorities are significantly more likely than Whites to be involved in community crime prevention. Sex was not a significant predictor of involvement.

When residents were sorted according to area violence levels, some differences in meaningful predictors emerged. In general, the same predictors that met significance for the entire sample were also significant for the areas with low to moderate violence levels. The one exception to this pattern was the fear variable, which was not significant for this group. However, when those neighborhoods with high violence levels are considered, differences are evident. For the attachment measures, feeling like they are part of the neighborhood and renters remain significant predictors, whereas relying on neighbors was no longer significant. Believing that police get to know residents and race also remained significant predictors, whereas fear, victimization, and social disorder were not significant in these high violent crime areas.

A similar pattern is evident when examining the neighborhoods sorted by arrest rates. Again the variables that meet significance in the low to moderate arrest areas are the same as those in the total sample, with the exception of fear, which was not significant in the moderate- to low-arrest areas. For the high-arrest areas, the findings were similar to those of high-violence areas, with one exception; in the high-arrest group, the renters variable was no longer significant. Race, the belief that police get to know residents, and feeling like part of the neighborhood were the significant predictors of involvement in high-arrest neighborhoods.

\section{Multivariate Analysis}

The results of our multivariate logistic regression analysis of the effect of individual- and community-level variables on citizen involvement are 


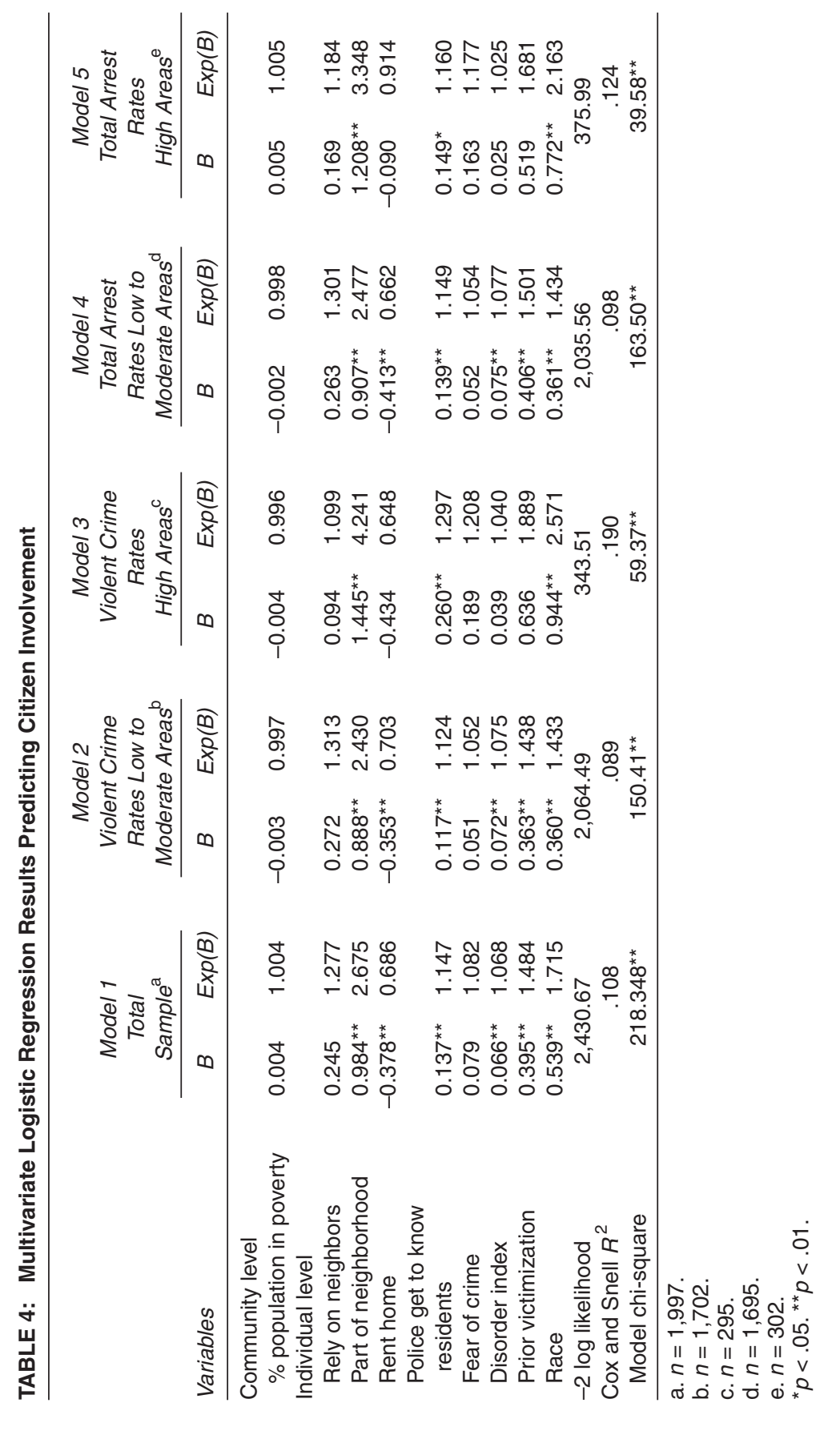


included in Table 4. To better understand the effect of person-environment interactions on citizen involvement, we estimated five separate logistic regression models. Included in our analysis were those predictor variables found to be significant at the bivariate level in either the overall or subgroup (by crime level and arrest level) analyses and include two measures of social cohesion (rely on neighbors and part of neighborhood), one measure of attitudes toward police (police get to know residents), a measure of disorder (disorder index), and other factors including prior victimization, fear of crime, and race.

Examination of Model 1 indicates that 6 of 8 factors are significant predictors of involvement. Those who feel like they are part of the neighborhood are significantly more likely to be involved in collective crime prevention when other factors are controlled. The size of this effect is worth noting. The odds of involvement are more than $150 \%$ ( $\operatorname{Exp} B=2.69)$ greater for those who feel like part of the neighborhood than those who do not have this attachment. Those who rent homes are significantly less likely to be involved. Those who believe police get to know residents are significantly more likely to be involved as are those who had higher scores on the disorder index. Those who had been victimized and minorities were also significantly more likely to be involved in collective crime prevention. The two variables not significant in this model were the rely on neighbors measure and fear of crime.

We have demonstrated that the level of community involvement is significantly higher in high-risk than low- to moderate-risk neighborhoods in Boston. To begin to answer the obvious question as to why these differences emerge, we examined the factors that helped explain variation in involvement in these two distinct subgroups of neighborhoods. Models 2 and 3 examine the effect of this same group of predictors on citizen involvement in neighborhoods. Model 2 includes the results for the low- to moderate-crime neighborhoods. The same predictors are significant in this model as those in the whole sample. These similar findings may be because the sample size for low to moderate crime ( $n=1,702$ residents in 122 neighborhoods) approaches the total sample size because only about 300 respondents reside in 41 high-crime areas.

To determine whether a similar pattern emerges among residents in highrisk neighborhoods, a separate model was estimated for the high-crime areas, as can be seen in Model 3 of Table 4. Examination of this model reveals a smaller set of predictor variables that help us explain citizen involvement in these high-risk neighborhoods. Significant predictors include feeling like part of the neighborhood, feeling that police get to know residents, and race. Surprisingly, the disorder index and renter status were not found to be signifi- 
cant predictors of involvement. In addition, neither prior victimization nor fear of crime were found to be related to citizen involvement. ${ }^{7}$

Comparisons between high-risk and low- to moderate-risk neighborhoods can also be made focusing on the relative strength of the relationship between individual predictors and community involvement. Based on these comparative logistic regression analyses, we conclude that although social cohesion (as measured by whether residents feel like they are part of the neighborhoods) is a strong predictor in both models, its effect on citizen involvement is much greater in high-risk than in low- to moderate-risk neighborhoods.

In the 41 high-risk (for violence) neighborhoods, residents who feel they are part of the neighborhood have odds of involvement that are 324\% greater $(\operatorname{Exp~B}=4.24)$ than those who feel it is a place to live. This is in comparison to the low to moderate neighborhoods where those who feel like they are a part have odds of involvement $143 \%$ greater than those who feel it is just a place to live. Similarly, minorities have odds of involvement that are $157 \%$ higher than Whites in high-risk neighborhoods compared to $43 \%$ higher than Whites in low-crime areas. By comparison, the differences in the effects of our community policing measure are smaller. Citizens in high-risk neighborhoods who reported that police get to know residents have odds of involvement that are $29 \%$ higher than those who do not feel police got to know residents, whereas residents in the low- to moderate-risk communities who reported that police get to know residents have odds of involvement that are only $12 \%$ higher than those who did not respond in this manner.

A final set of analyses was conducted to determine whether citizen involvement in collective crime prevention efforts is also affected by the level of policing in particular neighborhoods. Specifically, we examined residents living in areas with high overall arrest rates (neighborhoods with rates at or above the 75th percentile and those with low to moderate rates [neighborhoods with rates below the 75th percentile]. As we mentioned earlier, 30 of the 41 neighborhoods with high overall arrest rates also had high violent crime rates.

Models 4 and 5 (see Table 4) present the results of our logistic regression analysis of the correlates of citizen involvement in high- versus low- to moderate-arrest areas. Although the overall pattern of findings is quite similar to our analysis of high violent crime neighborhoods, some differences in the magnitude of individual predictors emerge, particularly in the high-arrest neighborhood analysis. Once again, only three significant predictors of citizen involvement were identified in the high-arrest neighborhood analysis. However, the size of the effects was noticeably lower for these three measures (part of neighborhood, police get to know residents, and race), perhaps because of the inclusion of residents living in low- to moderate-crime but 
high-arrest neighborhoods. Further analysis of citizen involvement across high-crime, high-arrest areas certainly will allow us to directly address this issue. Nonetheless, it does appear that whether you group Boston's neighborhoods by violent crime rates or overall arrest rates, not only does the level of involvement in community crime prevention but also the predictors of involvement vary significantly. We discuss the implications of these findings for theory, research, and policy in the following section.

\section{DISCUSSION}

Our research offers support for Gottfredson and Taylor's (1986) contention that there is a differential surveillance and control model operating at the neighborhood level. It does appear likely that both residents (via informal surveillance or control activities) and the police (via formal surveillance or control activities) respond differently to (high- and low-risk) offenders in different (high- vs. low-risk) neighborhoods. Although our research focused specifically on the question of differential involvement in crime prevention activities by residents in high-crime versus low- to moderate-crime areas, we suspect that offender risk level was one factor affecting level of involvement in high-risk neighborhoods. To the extent that a large proportion of all highrisk offenders reside in a small number of high-risk neighborhoods, it would certainly make sense to develop strategies aimed either at removing high-risk offenders from high-risk neighborhoods (via relocation strategies [Kling, Ludwig, \& Katz (2005)], perhaps tied to housing vouchers or some other form of incentive) or addressing the long-standing economic, social, and cultural problems that create and perpetuate these "poverty pockets" (Sampson \& Morenoff, 2006; Wilson, 1996). When viewed in this context, strategies aimed at convincing residents to take an active role in assisting the police in neighborhood-level surveillance and control appear to be misguided because they frame the policy question on the narrow topic of citizen involvement rather than the broader question of how to reverse the long-standing problems that characterize high-risk neighborhoods in urban areas across this country.

The analyses we completed provided the necessary answers to the four research questions we raised at the outset. First, we were able to determine that residents living in high-risk neighborhoods were actually more likely to become involved in community crime prevention efforts than residents living in low- to moderate-crime-risk neighborhoods. Second, our analysis underscored the critical link between one indicator of social cohesion (residents feel like they are part of the neighborhood) and involvement in crime preven- 
tion activities. Importantly, this measure of social cohesion was the strongest predictor of involvement in both high-risk and low- to moderate-risk neighborhoods. However, our finding that the second measure of social cohesion (rely on neighbors for help) was not a significant predictor of involvement provides support for Carr's (2003) contention that private networks of informal social control (relying on the direct support of more intimate networks such as neighbors) are being replaced by a combination of parochial and public social control networks. Furthermore, a comparison of the bivariate and multivariate analyses for high- and low- to moderate-risk neighborhoods reveals the breakdown of private social control networks is more pronounced in high-risk than low- to moderate-risk neighborhoods. It certainly seems plausible to argue that the failure of private social control networks is one likely explanation for why citizen involvement is so much higher in high-risk neighborhoods. When these private networks are missing, residents turn to parochial and public social control mechanisms, in large part because they have no place else to go. It is our contention that in high-risk neighborhoods, strategies need to be developed to improve private networks of informal social control and in the process reduce the stigma associated with living in (and returning to) these neighborhoods (Sampson \& Morenoff, 2004).

Focusing on the third question we raised about the link between public social control mechanisms (i.e., community policing activities) and citizen involvement in crime, it appears that involvement in crime prevention activities has less to do with the public's perception of the effectiveness of this public social control mechanism and more to do with the development of personal relationships between the police and residents in these areas. Our analyses revealed that regardless of neighborhood risk level, citizen involvement was not related to residents' perceptions that the police can prevent crime. However, citizens who reported that police get to know residents in their communities were more likely to get involved in both high-risk and lowto moderate-risk neighborhoods. ${ }^{8}$ The large effect sizes identified in highrisk neighborhoods suggest that when private control networks break down or are nonexistent in these neighborhoods, citizens turn to both parochial (i.e., community organizations, etc.) and public social control mechanisms (e.g., the police) for support and assistance. Once again, it appears that the findings here are consistent with Carr's (2003) recent ethnographic research on the emergence of a new parochialism in many neighborhoods. Because Carr's research was not conducted in a high-risk neighborhood, the findings reported here shed further light on exactly how this new parochialism may differentially affect high-risk versus low- to moderate-risk neighborhoods.

The final research question we raised focused on whether the individual characteristics (e.g., race, gender, prior victimization, fear), neighborhood 
perception indicators, and police perception measures used to predict citizen involvement had different effects in high-risk and low- to moderate-risk neighborhoods. As we anticipated from our review of the research on durable inequality and the emergence of poverty pockets (i.e., the existence of a relatively small number of high-crime neighborhoods in urban areas across the country where the crime problem appears to be linked to a unique set of causal mechanisms; Sampson \& Morenoff, 2004), the factors affecting citizen involvement in crime prevention varied (both in statistical significance and strength) by neighborhood crime risk levels. In high-risk neighborhoods, the following three factors emerged as significant predictors of citizen involvement: (a) Residents who felt like part of the neighborhood were more likely to be involved in crime prevention activities than were those who felt it was just a place to live. (b) Minority residents were more likely to be involved than were Whites. (c) Residents who believed that police get to know residents were more likely to be involved than were residents who did not feel this way about police.

By comparison, a more complex set of predictors was identified in our analysis of citizen involvement in low- to moderate-risk neighborhoods. In addition to the three predictors of involvement identified for the high-risk neighborhoods, three other significant predictors emerged: Renters were less likely to get involved than were owners; citizens who perceived higher levels of disorder were more likely to get involved; and citizens who had a prior victimization were also more likely to get involved. Taken together, these analyses suggest that citizen involvement in high-risk neighborhoods may be affected most by the unique blend of personal, parochial, and public social control mechanisms operating in these communities. Although it has been argued that the legitimacy of the police as perceived by residents may be a critical determinant of citizen involvement in crime prevention (e.g., Sherman, 2002), in areas characterized by high levels of crime, poverty, and minority residents, it is the emerging importance of the new parochialism that offers the most likely explanation for citizen involvement in crime prevention activities.

\section{NOTES}

1. Gottfredson and Taylor (1986) used median splits to dichotomize parolees and neighborhoods according to risk. For parolees, high risk was defined as an extensive prior record, either adult or juvenile, and low risk was defined as a moderate prior record. Type of neighborhood to which he or she was released was classified as high risk if it was above the median on an environmental incivilities scale and as low risk if it was below the median. 
2. The original sample included 3,046 residents. In all, $76 \%$ were successfully geocoded and are included in our analysis.

3. Both of our crime measures had an extreme outlier because of the low population used to calculate the rates in those areas.

4. For this question, no prompts were offered by the interviewer, but a follow-up question "like what" offered several choices to capture variation including joining community groups, increasing awareness or habits, working with outreach groups or with children, and socializing or meeting people.

5. Prior research suggests that opportunities for involvement vary across neighborhoods with different crime levels. The survey included a question on whether the respondents knew of any meetings held on public safety in their neighborhoods. We did find that the percentage of residents who knew of meetings was significantly higher in the high-crime neighborhoods.

6. We initially conducted a principal components analysis that generated a single factor for the structural characteristics percentage living in poverty, percentage Black, and percentage single-parent families. However, this factor was highly correlated with the individual-level race indicator, which we believe was a more important consideration for our purposes. As an alternative, we decided to include the major economic indicator for each neighborhood.

7. We caution the reader to consider the sample size differences across these two analyses, which may at least partially explain the larger number of predictors identified in the low to moderate crime areas.

8. A notable caveat to our analysis stems from the cross-sectional design-temporal ordering of variables cannot be determined. It could be that because of involvement, residents develop more favorable attitudes toward police. Our causal logic is consistent with prior research describing the relationship between community policing perceptions and involvement in crime prevention activities (Scheider, Rowell, \& Bezdikian, 2003).

\section{REFERENCES}

Buerger, M. E. (1994a). The limits of community. In D. P. Rosenbaum (Ed.), The challenge of community policing: Testing the promises (pp. 270-273). Thousand Oaks, CA: Sage.

Buerger, M. E. (1994b). A tale of two targets: Limitations of community anticrime actions. Crime \& Delinquency, 3, 411-436.

Bursik, R. J. (1988). Social disorganization and theories of crime and delinquency: Problems and prospects. Criminology, 26, 519-551.

Bursik, R. J., \& Grasmick, H. G. (1993). Neighborhoods and crime: Dimensions of effective community control. New York: Lexington Books.

Byrne, J., \& Sampson, R. J. (1986). The social ecology of crime. New York: Springer-Verlag.

Byrne, J., \& Taxman, F. (2004). Targeting for reentry: Inclusion/exclusion criteria across eight RPI programs. Federal Probation, 68(2), 53-61.

Carr, P. (2003). The new parochialism: The implications of the beltway case for arguments concerning informal social control. American Journal of Sociology, 108, 1249-1291.

Cordner, G. W. (1997). Community policing: Elements and effects. In R. G. Dunham \& G. P. Albert (Eds.), Critical issues in policing: Contemporary readings (pp. 451-468). Prospect Heights, IL: Waveland.

Frank, J., Brandl, S., Worden, R. E., \& Bynum, T. (1996). Citizen involvement in the coproduction of police outputs. Journal of Crime and Justice, 19, 1-30. 
Gottfredson, S. D., \& Taylor, R. B. (1986). Person-environment interactions in the prediction of recidivism. In J. M. Byrne \& R. J. Sampson (Eds.), The social ecology of crime (pp. 133-155). New York: Springer-Verlag.

Grinc, R. (1994). Angels in marble: Problems stimulating community involvement in community policing. Crime \& Delinquency, 40, 437-468.

Hawdon, J., \& Ryan, J. (2003). Police-resident interactions and satisfaction with police: An empirical test of community policing assertions. Criminal Justice Policy Review, 14, 55-74.

Kane, R. (2005). Compromised police legitimacy as a predictor of violent crime in structurally disadvantaged communities. Criminology, 43, 469-498.

Kerley, K. R., \& Benson, M. L. (2000). Does community-oriented policing help build stronger communities? Police Quarterly, 3(1), 46-69.

Kling, J., Ludwig, J., \& Katz, L. (2005). Neighborhood effects on crime for female and male youth: evidence from a randomized housing voucher experiment. Quarterly Journal of Economics, 120, 87-130.

Kubrin, C. E., \& Weitzer, R. (2003). New directions in social disorganization theory. Journal of Research in Crime \& Delinquency, 40, 374-402.

Lavrakas, P., \& Herz, E. (1982). Citizen participation in neighborhood crime prevention. Criminology, 20, 479-498.

Rosenbaum, D. P. (1998). Community crime prevention: A review and synthesis of the literature. Justice Quarterly, 5, 323-395.

Sampson, R. J., \& Groves, B. (1989). Community structure and crime: Testing social disorganization theory. American Journal of Sociology, 94, 774-802.

Sampson, R. J., \& Jeglum-Bartusch, D. (1998). Legal cynicism and subcultural tolerance of deviance: The neighborhood context of racial differences. Law and Society Review, 32, 777-803.

Sampson, R. J., \& Lauritsen, J. L. (1994). Violent victimization and offending: Individual-, situational-, and community level risk factors. In A. J. Reiss \& J. Roth (Eds.), Understanding and preventing violence (pp. 1-114). Washington, DC: National Academy Press.

Sampson, R. J., \& Morenoff, J. (2006). Durable inequality: Spatial dynamics, social processes, and the persistence of poverty in Chicago neighborhoods. In Poverty Traps, edited by S. Bowles, S. Durlauf, and K. Hoff. Princeton, NJ: Princeton University Press. Retrieved October 1, 2005, from http://www.wjh.harvard.edu/soc/faculty/sampson/

Sampson, R. J., Raudenbush, S. W., \& Earls, F. (1997). Neighborhood and violent crime: A multilevel study of collective efficacy. Science, 277, 918-924.

Sampson, R. J., \& Wilson, W. J. (1995). Toward a theory of race, crime, and urban inequality. In J. Hagan \& R. Peterson (Eds.), Crime and inequality (pp. 37-56). Stanford, CA: Stanford University Press.

Schafer, J. A., Huebner, B., \& Bynum, T. (2003). Citizen perceptions of police services. Police Quarterly, 6, 440-468,

Scheider, M. C., Rowell, T., \& Bezdikian, V. (2003). The impact of citizen perceptions of community policing on fear of crime: Findings from twelve cities. Police Quarterly, 6, 363-386.

Shaw, C. R., \& McKay, H. D. (1942). Juvenile delinquency in urban areas. Chicago: University of Chicago Press.

Sherman, L. (2002). Trust and confidence in criminal justice. In J. Victor \& J. Naughton (Eds.), Annual editions: Criminal justice 2004/2005 (pp. 40-47). Dubuque, IA: McGraw-Hill/ Dushkin.

Skogan, W. G. (1989). Communities crime and neighborhood organization. Crime \& Delinquency, 35, 437-457.

Skogan, W. G. (1990). Disorder and decline: Crime and the spiral decay in American neighborhoods. New York: Free Press. 
Skogan, W. G., \& Hartnett, S. M. (1997). Community policing, Chicago style. New York: Oxford University Press.

Smith, B., Novak, K., \& Hurley, D. (1997). Neighborhood crime prevention: The influences of community-based organizations and neighborhood watch. Journal of Crime and Justice, 20 , 69-86.

Wilson, W. J. (1996). When work disappears: The world of the new urban poor. New York: Knopf. 